Polymer Journal, Vol. 39, No. 11, pp. 1172-1176 (2007)

(C)2007 The Society of Polymer Science, Japan

\title{
Electroactive Azo Polyamide Based Oligoaniline: Synthesis and Characterization
}

\author{
Li-Bing HE, Hua-Ping MAO, Dan-Ming CHAO, and Wan-Jin ZHANG ${ }^{\dagger}$ \\ Alan G. MacDiarmid Institute, Jilin University, Changchun, 130012, P. R. China
}

(Received April 27, 2007; Accepted August 11, 2007; Published September 26, 2007)

\begin{abstract}
An alternating copolymer, electroactive azo polyamide was prepared by oxidative coupling polymerization of oligoaniline macromonomer and p-phenylenediamine. The molecular structure of the polyamide was characterized by Fourier-transform infrared (FT/IR) spectra, ${ }^{1} \mathrm{H}$ NMR spectroscopy, elemental analysis (EA) and gel permeation chromatography (GPC). UV-vis spectrum was used to monitor the chemical oxidation process and the photoisomerization of the polymer. The electrochemical activity of the polyamide was checked by cyclic voltammetry (CV) and the mechanism of electrochemical oxidation process was well studied. Moreover, the thermal characteristics of the polyamide were evaluated by thermogravimetric analysis (TGA). [doi:10.1295/polymj.PJ2007025]

KEY WORDS Electroactive / Azo Polyamide / Oligoaniline / Oxidative Coupling / Photoisomerization /
\end{abstract}

Azobenzene polymers are promising materials for optical switching and digital optical storage, due to the possibility of changing the orientation of the azobenzene chromophores by irradiation with polarized light. ${ }^{1}$ In the need for polymer materials is changing from structural materials to functional materials, the current trend is to employ the azobenzene moiety as a "trigger" to induce morphological changes which can be light driven. ${ }^{2}$ The possibility thus arises that since conformations of azobenzene-containing polymers can be controlled by using photoinduced changes of the azobenzene moiety, they may provide light-controlled chemical functions. Expectedly, this would lead to the possibility of controlling the chemical functions by an "on-off light switch." Among conductive polymers, polyaniline (PANI) is remarkable for its excellent environmental stability, ${ }^{3}$ and unique in the ease with which its properties may be tuned by changes in oxidation state ${ }^{4}$ or in degree of protonation. ${ }^{5}$ Incorporation of a well-define oligoaniline into azo polyamide ${ }^{6-8}$ leads to polymers not only with photoactivity but also with electroactivity.

Bearing all this in mind, a new polyamide with azobenzene and amine-capped aniline pentamer in the main chain was synthesized successfully. And the polyamide was studieded by FT/IR spectra, ${ }^{1} \mathrm{H}-\mathrm{NMR}$ spectroscopy, elemental analysis, GPC, UV-vis spectra, CV and TGA. What made us excited was that the photoisomerization of the polymer, which maybe could provide light-controlled chemical functions occurred with the irradiation of UV light.

\section{EXPERIMENTAL}

\section{Materials}

All chemicals, dichloromethane (99\%), hydrochloric acid (37\%), N, N'-dimethylformamide (DMF, 99\%), N-methyl-2-pyrrolidinone (NMP, 99\%), tetrahydrofuran (99\%), ammonium persulfate (98\%), Nphenyl-p-phenylenediamine $(98 \%), p$-phenylenediamine (99\%), diethyl ether (99\%), triethylamine $(99 \%)$ were used as received without further purification.

\section{Instruments}

Mass spectra (MS) was performed on an AXIMACFR laser desorption ionization flying time spectrometer (COMPACT). FT/IR measurements were recorded on a BRUKER VECTOR 22 Spectrometer. The samples were mixed with $\mathrm{KBr}$ and pressed into a plate for measurement at $25^{\circ} \mathrm{C}$. The ${ }^{1} \mathrm{H}$ NMR spectra of trans-Azobenzene-4,4'-dicarbonyl chloride in deuterated chloroform $\left(\mathrm{CDCl}_{3}\right)$ and the polyamide in deuterateddimethyl sulfoxide (DMSO) were run on a BRUKER-500 spectrometer to determine the chemical structure and tetramethylsilane was used as the internal standard. UV-vis spectra were performed on UV-3101 PC Spectrometer (SHIMADZU) in NMP. The cyclic voltammetry $(\mathrm{CV})$ was performed with a CHI 660A Electrochemical Workstation (CH Instruments, USA) in a conventional three-electrode cell by using thin films cast from DMF solutions onto a glassy carbon electrode. The film was cycled in $1.0 \mathrm{M} \mathrm{H}_{2} \mathrm{SO}_{4}$ aqueous solution in the range from

${ }^{\dagger}$ To whom correspondence should be addressed (Tel: +86-431-85168924, Fax: +86-431-85168924, E-mail: wjzhang @jlu.edu.cn). 

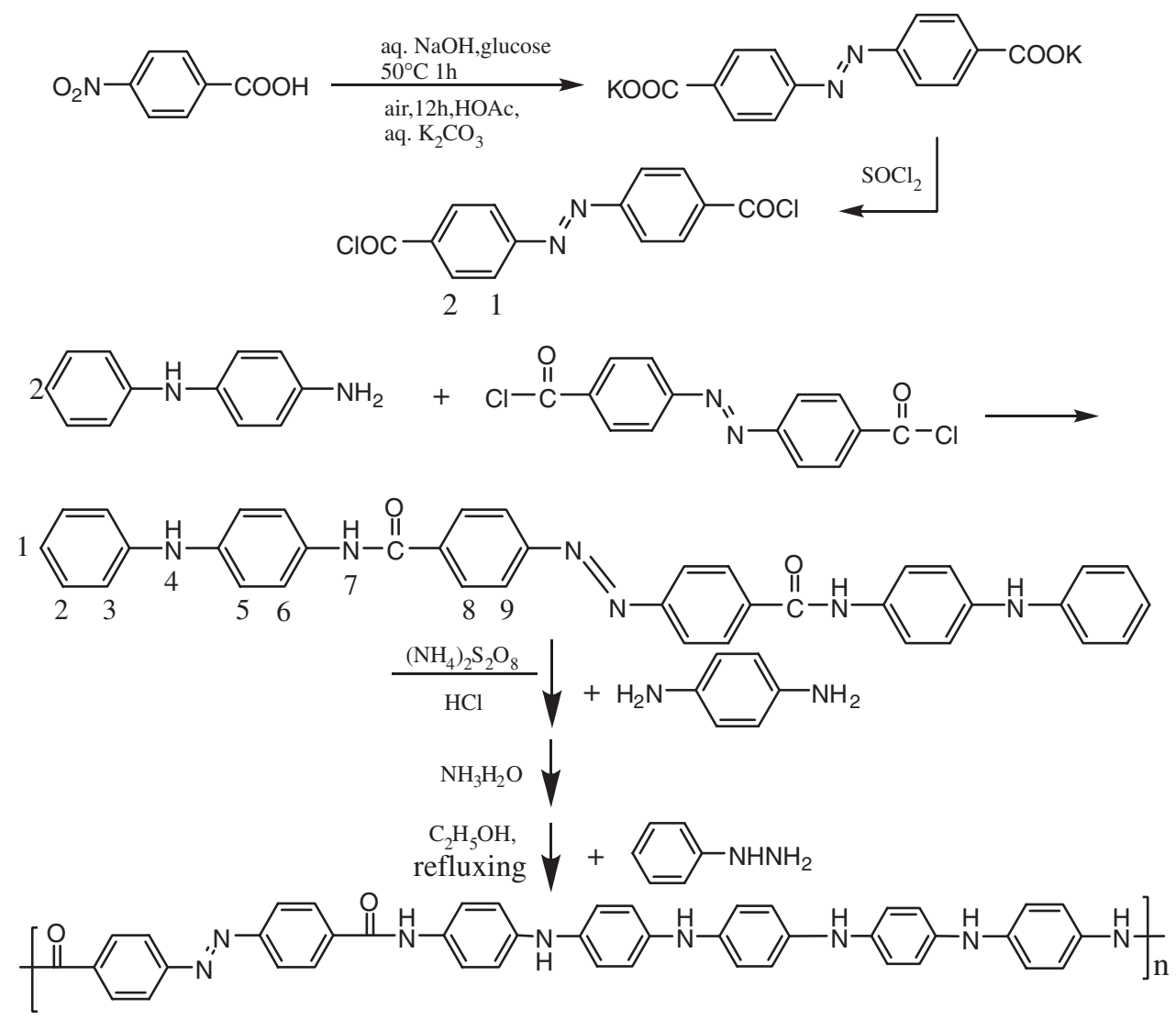

Scheme 1. Synthesis of the monomer and electroactive azo polyamide.

$0 \mathrm{mV}$ to $900 \mathrm{mV}$. A Perkin-Elmer PYRIS 1 TGA was used to investigate the thermal stability of the polyamide in the temperature range from $100^{\circ} \mathrm{C}$ to $800^{\circ} \mathrm{C}$ under nitrogen protection. The weight percentages of carbon, hydrogen, nitrogen and oxygen in the samples were measured by a Flash Ea 1112 elemental analysis instrument. The molecular weight of polyamide was measured with Shimadzu GPC-802D gel column and SPD-M10AVP detector.

Synthesis of trans-azobenzene-4,4'-dicarbonyl chloride

The synthetic route for the preparation of trans-azobenzene-4, 4'-dicarbonyl chloride is depicted in Scheme 1. Suitable preparation for trans-azobenzene-4, 4'-dicarbonyl chloride has been reported in the literature ${ }^{9}$ in $56.7 \%$ yield.

Characterization of trans-azobenzene-4,4'-dicarbonyl chloride:

${ }^{1} \mathrm{H} \mathrm{NMR}\left(\mathrm{CDCl}_{3}\right): \delta=8.08\left(\mathrm{~d}, 4 \mathrm{H}\right.$, due to $\left.\mathrm{H}_{1}\right)$, $\delta=8.33\left(\mathrm{~d}, 4 \mathrm{H}\right.$, due to $\left.\mathrm{H}_{2}\right)$.

FT/IR $\left(\mathrm{cm}^{-1}\right)$ : 3428, 3095, 1594, 1405, 1774, 1731, 1195, 887, 1006, 800.

Elem. Anal: $\left(\mathrm{C}_{14} \mathrm{H}_{8} \mathrm{Cl}_{2} \mathrm{~N}_{2} \mathrm{O}_{4}\right)$ calculated: $\mathrm{C}, 49.58 ; \mathrm{H}$, 2.38; N, 8.26; O, 18.87; found: C, 49.67; H, 2.19; N, $8.21 ; \mathrm{O}, 18.95$.

\section{Synthesis of monomer}

A solution of trans-azobenzene-4,4'-dicarbonyl chloride $0.61 \mathrm{~g}$ ( $2 \mathrm{mmol})$ in $10 \mathrm{~mL}$ of dichloromethane was added dropwise over a period of $10 \mathrm{~min}$ to a stirring mixture of $\mathrm{N}$-phenyl-p-phenylenediamine $(0.92 \mathrm{~g}$, $5 \mathrm{mmol})$ and triethylamine $(3 \mathrm{~mL})$ in $30 \mathrm{~mL}$ of dichloromethane. The reaction proceeded readily at room temperature with the formation of a light yellow solution. The reaction mixture was stirred for $3 \mathrm{~h}$ which yielded a buff precipitate that was suction filtered and subsequently washed with dichloromethane, pure water and diethyl ether. After drying in vacuo at $50^{\circ} \mathrm{C}$ for $24 \mathrm{~h}$, analytically pure monomer was obtained in $81.7 \%$ yield.

Characterization of the macromonomer:

MALDI-TOF-MS: $m / z$ calculated for $\mathrm{C}_{38} \mathrm{H}_{30} \mathrm{~N}_{6} \mathrm{O}_{2}$ 602.3. Found 601.3.

${ }^{1} \mathrm{H}$ NMR $\left(\mathrm{d}_{6}-\mathrm{DMSO}\right): \delta=6.79$ (t, $2 \mathrm{H}$, due to $\mathrm{H}_{1}$ ), $\delta=7.22\left(\mathrm{t}, 4 \mathrm{H}\right.$, due to $\left.\mathrm{H}_{2}\right), \delta=7.10(\mathrm{~d}, 4 \mathrm{H}$, due to $\left.\mathrm{H}_{3}\right), \delta=8.15\left(\mathrm{~s}, 2 \mathrm{H}\right.$, due to $\left.\mathrm{H}_{4}\right), \delta=7.05(\mathrm{~d}, 4 \mathrm{H}$, due to $\left.\mathrm{H}_{5}\right), \delta=7.68\left(\mathrm{~d}, 4 \mathrm{H}\right.$, due to $\left.\mathrm{H}_{6}\right), \delta=10.34$ $\left(\mathrm{s}, 2 \mathrm{H}\right.$, due to $\left.\mathrm{H}_{7}\right), \delta=8.07\left(\mathrm{~d}, 4 \mathrm{H}\right.$, due to $\left.\mathrm{H}_{8}\right)$, $\delta=8.20\left(\mathrm{~d}, 4 \mathrm{H}\right.$, due to $\left.\mathrm{H}_{9}\right)$.

FT/IR $\left(\mathrm{cm}^{-1}\right)$ : 3396, 3259, 3052, 1647, 1598, 1517, 1440, 1398, 1319, 1261, 1236, 862, 825, 742, 694; Elem. Anal: $\left(\mathrm{C}_{38} \mathrm{H}_{30} \mathrm{~N}_{6} \mathrm{O}_{2}\right)$ calculated: $\mathrm{C}, 75.73 ; \mathrm{H}$, 
5.02; N, 13.94; O, 5.31; found: C, 75.52, H, 5.13, N, $13.78, \mathrm{O}, 5.44$.

\section{Synthesis of electroactive azo polyamide}

$0.6027 \mathrm{~g}(1 \mathrm{mmol})$ of the monomer and $0.1081 \mathrm{~g}$ $(1 \mathrm{mmol}) \mathrm{p}$-phenylenediamine were dissolved in mixture solution $(10 \mathrm{~mL}$ DMF and $1.2 \mathrm{~mL}$ concentrated hydrochloric acid). A solution of ammonium persulfate $\left(\left(\mathrm{NH}_{4}\right)_{2} \mathrm{~S}_{2} \mathrm{O}_{8} 0.456 \mathrm{~g}\right.$ in $1 \mathrm{~mL} 1.0 \mathrm{M} \mathrm{HCl}$ aqueous solution) was added dropwise over a period of $5 \mathrm{~min}$ to the above-mentioned solution, with magnetic stirring at room temperature. After the addition, the resulting solution reacted for $10 \mathrm{~h}$. Then it was poured into $100 \mathrm{~mL}$ distilled water to precipitate the product and then suction filtered. The precipitate was washed with distilled water for three times, after washing with tetrahydrofuran it was dried in a vacuum oven at $50^{\circ} \mathrm{C}$ for $24 \mathrm{~h}$. The product was dedoped by $1 \mathrm{M}$ ammonium hydroxide, then was reduced by phenylhydrazine in $100 \mathrm{~mL}$ ethanol. Black powder was got in $71 \%$ yield. $M_{\mathrm{n}}: 9600, M_{\mathrm{w}}: 11500, M_{\mathrm{w}} / M_{\mathrm{n}}: 1.20$.

FT/IR $\left(\mathrm{cm}^{-1}\right)$ : 3396, 3262, 3050, 1646, 1600, 1518, 1440, 1398, 1307, 1261, 1232, 863, 821, 744, 694.

${ }^{1} \mathrm{H}$ NMR $\left(\mathrm{d}_{6}\right.$-DMSO): $\delta=10.31-10.19(\mathrm{~m}, 2 \mathrm{H},-\mathrm{CO}-$ $\mathrm{NH}-), \delta=8.19$ (s, 4H, Ar-H), $\delta=8.12$ (s, 2H, -NH-), $\delta=8.06(\mathrm{~s}, 4 \mathrm{H}, \mathrm{Ar}-\mathrm{H}), \delta=7.76-7.55(\mathrm{~m}, \mathrm{Ar}-\mathrm{H}), \delta=$ 7.24-7.05 (m, Ar-H), $\delta=7.02-6.88(\mathrm{~m}$, Ar-H) $\delta=$ 6.80-6.51 (m, Ar-H). Elem. Anal: $\left(\mathrm{C}_{44} \mathrm{H}_{34} \mathrm{~N}_{8} \mathrm{O}_{2}\right)$ calculated: C, 74.77; H, 4.85; N, 15.85; O, 4.53; found: C, 74.53; H, 4.93; N, 15.78; O, 4.76 .

\section{RESULTS AND DISCUSSIONS}

Scheme 1 showed the synthetic route to the electroactive azo polyamide. In this synthetic approach, we synthesized the polyamide by oxidative coupling polymerization at room temperature instead of the polycondensation initiated by amine-capped aniline pentamer and acyl chlorides. The structure and properties of the macomonomer and electroactive polyamide were characterized by MS, NMR, FT/IR, GPC, TGA, UV-vis and CV.

The TGA curve of the pure polymer was represented in Figure 1. It indicated that the polymer had a general thermal resistance with a weight loss of $5 \%$ at around $384{ }^{\circ} \mathrm{C}$ under nitrogen atmosphere. Three steps weight loss just like the copolymer ${ }^{10}$ which was studied previously. The polymer had a quite excellent thermal stability.

The polymer in the leucoemeraldine oxidation state was dissolved in NMP solution. Trance amount of $\left(\mathrm{NH}_{4}\right)_{2} \mathrm{~S}_{2} \mathrm{O}_{8}$ was added to it. The solution gradually turned to blue and finally light purple upon being oxidized. This process was monitored by UV-vis spectra continuously; UV-vis spectra obtained is shown in

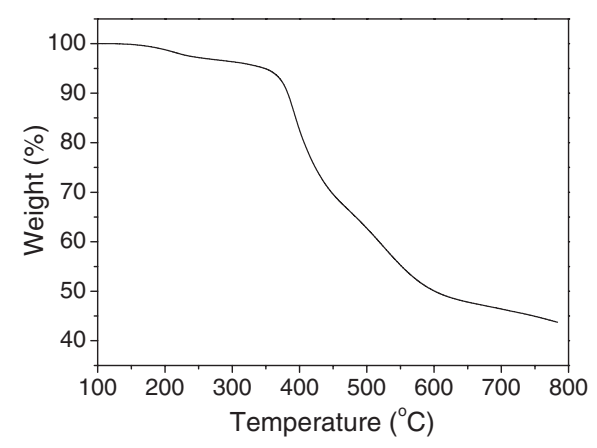

Figure 1. TGA thermogram of electroactive azo polyamide.

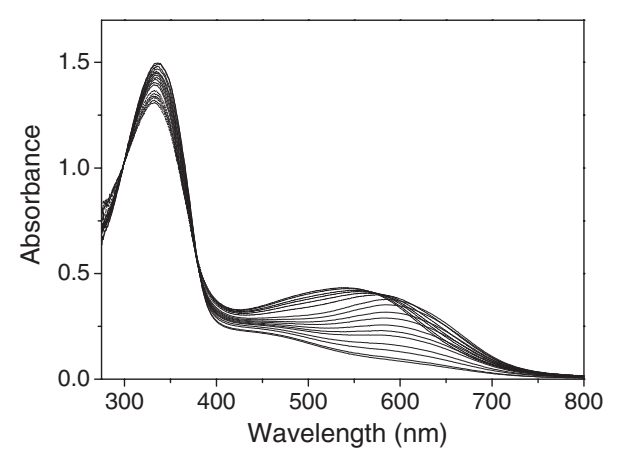

Figure 2. UV-vis spectra monitoring chemical oxidation of the polymer in the leucoemeraldine oxidation state.

Figure 2. First only one absorption at $336 \mathrm{~nm}$ was observed which is associated with $\pi-\pi^{*}$ transition of the conjugated ring system and trans-azobenzene group. ${ }^{2,11,12}$ When it was slowly oxidized, the UVvis spectra showed a new absorption at about 583 $\mathrm{nm}$, which is assigned to the benzenoid to quiniod excitonic transition ${ }^{13}$ and continually increased in intensity. The $\lambda_{\max }$ of the second absorption began to undergo a blue shift (from $583 \mathrm{~nm}$ to $536 \mathrm{~nm}$ ) before its intensity reached the maximum. A possible explanation (Scheme 2) of this phenomenon is that there are two emeraldine oxidation states in the continuous oxidation. The chemical oxidation process is similar to that of oligoaniline.

In order to study its cis-trans isomerization, the polymer was dissolved in NMP solution and UV-vis spectra changes were monitored during the UV light irradiation (Figure 3). As shown in Figure 3, the intensity of the absorption at $336 \mathrm{~nm}$, which was associated with $\pi-\pi^{*}$ transition of the conjugated ring system and trans-azobenzene group, gradually decreased as the time of irradiation increased. And correspondingly, the absorption at $573 \mathrm{~nm}$ associated with $\mathrm{n}-\pi^{*}$ transition of the cis-azobenzene group increased gradually. Compared with azobenzene which had a absorption band appeared at about $450 \mathrm{~nm}$, the absorption band of $n-\pi^{*}$ transition of the cis-azobenzene group had a red shift. The explanation to that was 


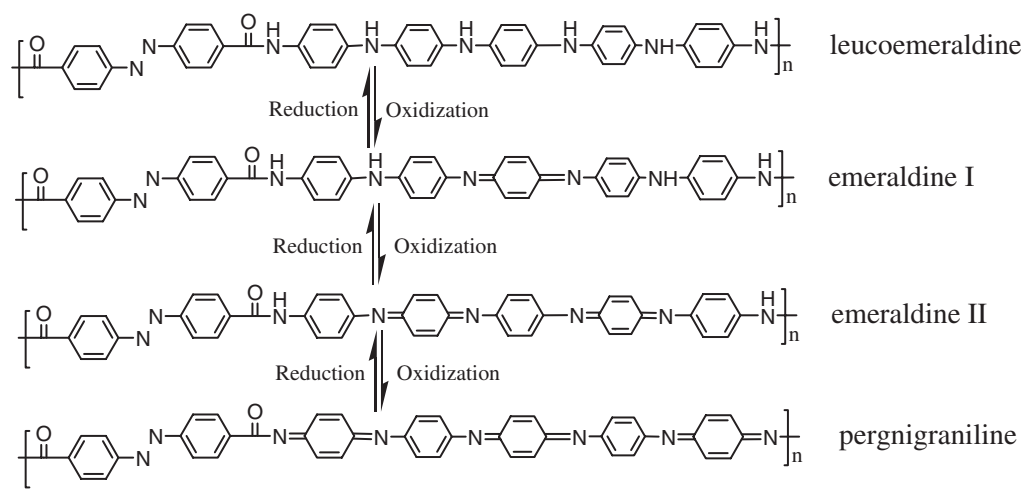

Scheme 2. Molecular structures of the electroactive polyamide at various oxidation states.

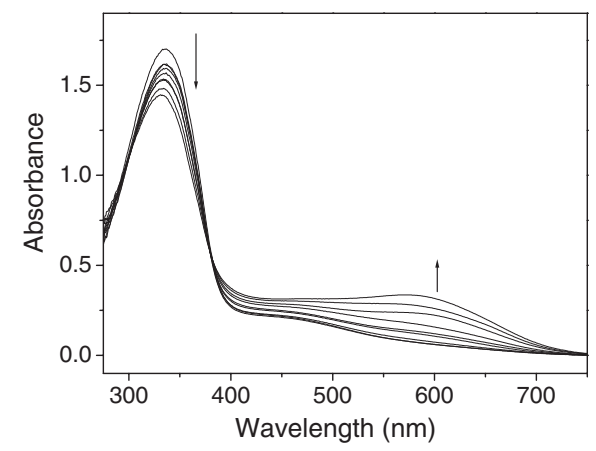

Figure 3. UV-vis spectra changes during the UV light irradiation.

given below: Because the ultraviolet light we used was very week, the monitoring procedure had cost quite a long time. During that period, the cis-trans transition of the azobenzene groups and the oxidation of the aniline segments which was caused by UV light and oxygen, were occurring at the same time. Therefore, Figure 3 showed superposition UV-vis spectra changes in fact. And the further research is ongoing in order to get an overall understanding of that.

The electrochemical behavior of the polymer in $1 \mathrm{M}$ $\mathrm{H}_{2} \mathrm{SO}_{4}$ was also studied. The DMF solution of the polymer was cast on the glassy carbon working electrode and was evaporated to form thin solid film. Under these conditions, the cyclic voltammogram (Figure 4) of the polymer showed three pairs of redox peaks, different from PANI which has two pairs of redox peaks in the cyclic voltammogram. ${ }^{14} \mathrm{We}$ proposed that the first oxidation peak at $310 \mathrm{mV}$ corresponds to the transition from the leucoemeraldine state to the first emeraldine state, The second oxidation peak at $540 \mathrm{mV}$ was assigned to the transition from the first emeraldine state to the second emeraldine state and the last oxidation peak at $714 \mathrm{mV}$ was due to the transition from the second emeraldine oxidation state to the pernigraniline oxidation state (Scheme 2). It was similar to the oxidation proceed with the polymer ${ }^{10,15,16}$ which we reported previously.

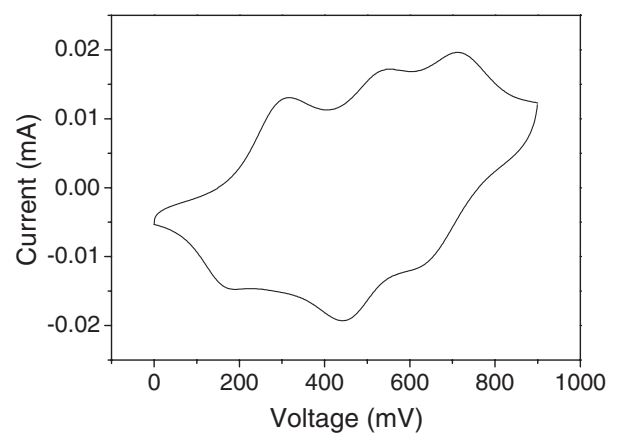

Figure 4. Cyclic voltammetry of electroactive azo polyamide.

In summary, an electroactive azo polyamide was synthesis successfully by oxidative coupling polymerization in room temperature. It can change its oxidation states and isomerization with stimulation and its stability is excellent. The electroactive azo polyamide can be represented as a genuine molecular composite material. With a not too bad solubility and excellent thermal stability, it might provide an opportunity for solving the problems that exist in traditional conductive polymer composites materials. ${ }^{17,18}$

Acknowledgment. The financial support from the National Natural Science Foundation of China (NNSFC-50473007 and NNSFC-20674027) and the National Major Project for Fundamental Research of China (National 973 Program No G2003CB615604) is greatly appreciated.

\section{REFERENCES}

1. A. Natansohn and P. Rochon, Adv. Mater., 11, 1387 (1999).

2. G. S. Kumar, Chem. Rev., 89, 1915 (1989).

3. W. S. Huang, B. D. Humphrey, and A. G. MacDiarmid, J. Chem. Soc., Faraday Trans., 82, 2385 (1986).

4. E. W. Paul, A. J. Ricco, and M. S. Wrighton, J. Phys. Chem., 89, 1441 (1985).

5. J. C. Chiang and A. G. MacDiarmid, Synth. Met., 13, 193 (1986).

6. J. E. Riordan and H. S. Blair, Polymer, 20, 196 (1979). 
7. E. S. Balcerzak, B. Sapich, and J. Stumpe, Polymer, 46, 49 (2005).

8. G. Iftime, A. Natansohn, and P. Rochon, Macromolecules, 35, 365 (2002).

9. G. D. Jaycox, Polymer, 39, 2589 (1998).

10. D. M. Chao, X. F. Lu, J. Y. Chen, X. G. Zhao, L. F. Wang, W. J. Zhang, and Y. Wei, J. Polym. Sci., Part A: Polym. Chem., 44, 477 (2006).

11. E. Conwell, C. B. Duke, A. Paton, and S. Leyadev, J. Chem. Phys., 88, 3955 (1988).

12. J. Honzl and M. Tlustakova, Tetrahedron, 25, 3641 (1969).

13. Y. Furukawa, F. Ueda, Y. Hyodo, and I. Harada, Macromolecules, 21, 1297 (1988).
14. J. B. Gao, D. G. Liu, J. M. Sansinena, and H. L. Wang, $A d v$. Funct. Mater., 14, 537 (2004).

15. L. Chen, Y. H. Yu, H. P. Mao, X. F. Lu, L. Yao, W. J. Zhang, and Y. Wei, Chem. J. Chinese. Universities, 9, 1768 (2004).

16. L. Chen, Y. H. Yu, H. P. Mao, X. F. Lu, L.Yao, W. J. Zhang, and Y. Wei, Chem. J. Chinese. Universities, 9, 1768 (2004).

17. "Handbook of Conducting Polymers" 2nd ed., T. A. Skotheim, R. L. Elsenbaumer, and J. R. Reynolds, Ed., Marcel Dekker, New York, 1998.

18. E. M. Genies, A. Boyle, M. Lapkoski, and C. Tsintaris, Synth. Met., 36, 139 (1990). 